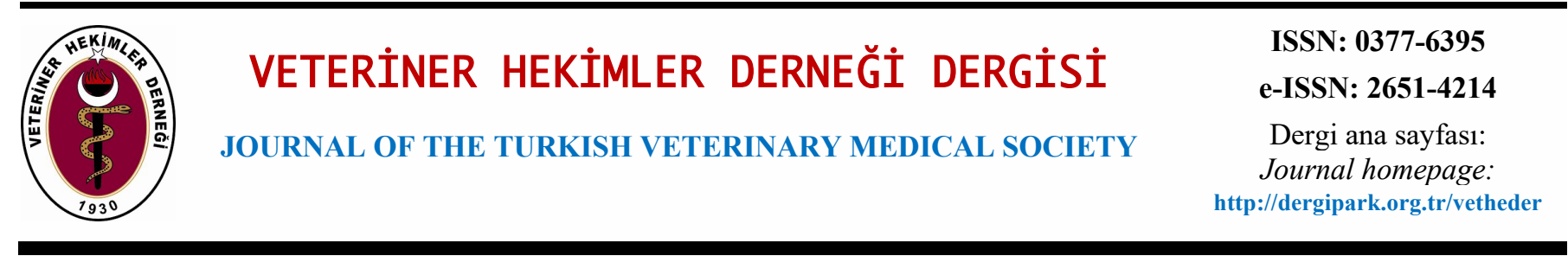

DOI: $10.33188 /$ vetheder.875381

Derleme / Review

\title{
Kanatlılarda kontakt dermatit
}

\author{
Hilal ÇAPAR AKYÜZ ${ }^{1, a^{*}}$, E. Ebru ONBAŞILAR ${ }^{1, b}$ \\ ${ }^{1}$ Ankara Üniversitesi, Veteriner Fakültesi, Zootekni Anabilim Dall, Ankara, Türkiye \\ ORCID: 0000-0002-4741-6893 ; 0000-0002-1321-0280
}

MAKALE BILGISI /
ARTICLE
INFORMATION:
Geliş / Received:
05 Şubat 2021
05 Febuary 2021
Kabul / Accepted:
02 Mayıs 2021
02 May 2021
Anahtar Sözcükler:
Kontakt dermatit
Kanatlı
Hayvan refahı
Keywords:
Contact dermatitis
Poultry
Animal welfare

Animal welfare
ÖZET:

\begin{abstract}
Kontakt dermatit, kanatlılarda yaygın görülen bir deri problemidir. Bu hastalık hayvan refahının belirlenmesinde önemli rol oynamaktadır. Üretici bakımından ise önemli ekonomik kayıplara yol açabilmektedir. Enfeksiyöz olmayan bu hastalık ayak tabanı (ayak tabanı yanı̆̆ı), diz (diz yanığı) ve göğüsü (göğüs yanığı) etkilemektedir. Hastalığın ortaya çıkmasında; genotip, cinsiyet, canlı ağırlık, beslenme, bağırsak enfeksiyonları, altlık özellikleri ve kümes koşulları gibi pek çok faktör etkili olabilmektedir. Başlıca nedeni ise altlıktaki nem içeriğinin yüksek olmasıdır. Altlıktaki nem oranını etkileyen faktörler; altığın türü, altık derinliği, çevre sıcaklığı, havalandırma, nispi nem, suluk idaresi ve birim alandaki piliç yoğunluğu olarak sıralanabilmektedir. Genotip bu hastalığın ortaya çıkmasındaki diğer önemli faktördür. Hızlı büyüyen piliçlerde canlı ağırlık arttıkça yürüme yeteneğinde bozulmalar meydana gelmekte ve bu durum ayak tabanı ile diz yanık oranlarını artırmaktadır. Göğüs yanıkları ayrıca yüksek göğüs ağırlığı ve zayıf göğüs tüylenmesi ile ilişkilendirilebilmektedir. Kontakt dermatit etçi piliçlerde, hindilerde ve Pekin ördeklerinde tespit edilmiştir. Özellikle hindilerde görülme sıklığı etçi piliçlere göre daha fazla olmaktadır. Bununla birlikte altlıklı sistemde yetiştirilen yumurtacı tavuklar ile etçi piliç damızlıklarda da görülebilmektedir. Kontakt dermatitin önlenmesinde kümes içi koşullar ön plana çıkmaktadır. Refah kriterleri göz önüne alınarak yapılan kanatlı hayvan yetiştiriciliğinde, kontakt dermatit yaygınlığının azalacağı ön görülmektedir.
\end{abstract}

\section{Contact dermatitis in poultry}

ABSTRACT:

Contact dermatitis is a common skin problem in poultry. This disease plays an important role in determining animal welfare. In terms of the producer, it can cause significant economic losses. This non-infectious disease affects the foot pad (foot pad dermatitis), hock (hock burn) and breast (breast burn). Many factors such as genotype, sex, body weight, nutrition, intestinal infections, litter quality and poultry house conditions can be effective to emergence of the disease. The main reason is high moisture content in the litter. Factors affecting the moisture ratio in litter; litter type, litter depth, ambient temperature, ventilation, relative humidity, drinker management and broiler density per unit area. Genotype is another important factor in the occurrence of this disease. As body weight increases in fast-growing broilers, walking ability deteriorates and this rises the rates of foot pad dermatitis and hock burns. Breast burns can also be associated with high breast weight and poor breast feathering. Contact dermatitis has been detected in broilers, turkeys and pekin ducks. Especially in turkeys, its incidence is higher than in broilers. However, it can be seen in laying hens and broiler breeders raised in the litter system. In the prevention of contact dermatitis, poultry house conditions are prominent. It is predicted that the prevalence of contact dermatitis will decrease in poultry breeding based on the welfare criteria.

How to cite this article: Akyüz HÇ, Onbaşilar EE: Kanatl1larda kontakt dermatit. Veteriner Hekimler Dernegi Dergisi, 92(2): 188-197, 2021, Doi: $10.33188 /$ vetheder. 875381 


\section{Giriş}

Kontakt dermatit kanatlllarda zemin, altlık ve tünek gibi sert yüzeyler ile temas eden derinin epidermis tabakasında oluşan enfeksiyöz olmayan lezyonlardır $(29,35)$. Kontakt dermatit; ayak tabanı, diz ve göğüste yanıklar şeklinde görülmektedir (35). Bu lezyonlar deride renk değişimi ile başlamakta, ileri aşamasında ülsere neden olmaktadır (54). Ayrıca söz konusu lezyonlar ağrı, sekonder enfeksiyonlar, bacak ve eklem sorunlarına da neden olabilmektedir (49, 31). Ayak tabanı yanıkları ilk olarak 1980'lerde bildirilmiştir $(30,52)$, ve günümüzde ekonomik kayıplara yol açmakla birlikte bir refah kriteri olarak da değerlendirilmektedir $(32,23,75)$. Avrupa Birliği’nde 2007 yılında yürürlüğe giren mevzuata göre, kanatlı hayvan yetiştiriciliği yapan ticari çiftliklerde ayak tabanı dermatitlerinin görülme oranını azaltılmak amacıyla kümeslerdeki yerleşim sıklığının kontrol altında tutulması gerektiği bildirilmiştir (27). Alınan karara göre piliç kümeslerinde maksimum yoğunluk $39 \mathrm{~kg} / \mathrm{m}^{2}$ olmalıdır. Bununla birlikte belirli kriterler yerine getirilmesi şartıyla, yoğunluk $3 \mathrm{~kg} / \mathrm{m}^{2}$ fazladan artırılabilmektedir. Fakat en uygun yoğunluk $35 \mathrm{~kg} / \mathrm{m}^{2}$ olarak kabul edilmektedir (45).

Dermatitlerin görülme sıklı̆̆ etçi piliçlerde daha çok olmakla birlikte, altlıklı sistemlerde yetiştirilen yumurtacı ve damılık tavuklarda da görülmektedir $(71,37)$. Ayak tabanı yanıkları etçi piliçlerde üretimin üçüncü haftasında görülmeye başlamaktadır (70). Haslam ve ark. (32), yaptıkları çalışmada her bir etçi piliç sürüsünde orta veya şiddetli düzeyde dermatit görülme yüzdesini; ayak tabanında \% 11.02, dizde \% 1.29 ve göğüste \% 0.02 olduğunu bildirmişlerdir. Souillard ve ark., (64) yaptıkları çalışmada organik etçi piliçlerde \% 21.9 düzeyinde ayak tabanı yanıklarının oluştuğunu tespit etmişlerdir. Kontakt dermatit görülme oranını mevsim de etkileyebilmektedir. Dinev ve ark., (22) mevsimin etkisini inceledikleri çalışmalarında etçi piliçlerde kontakt dermatitlerin en çok \% 12.77 oranı ile sonbahar-kış ve ilkbahar mevsimlerinde, en düşük de \% 9.1 oranı ile yaz mevsiminde görüldüğünü bildirilmişlerdir. Diğer yandan kontakt dermatit görülme oranı kanatlı türlerine göre de değişiklik göstermektedir. Hindilerde ayak tabanı yanıkları etçi piliçlere göre daha sık oluşmaktadır. Bunun nedeni hindilerin etçi piliçlere göre daha ileri yaşta kesilmesinden kaynaklandığı düşünülmektedir (35). Krautwald-Junghanns ve ark (42), 2007-2012 yılları arasında hindiler üzerine yaptıkları çalışmada; hindilerin hepsinde ayak tabanı yanı̆̆ı tespit etmişlerdir. Bu çalışmaya göre lezyonların \% 63.3'ü yetiştiriciliğin ilk haftasında görülmeye başlanmakta ve özellikle 22-35 günlük yaşlarda artış göstermektedir. Bununla birlikte ayak tabanı yanıkları hindilerde en çok Ekim-Ocak ayları arasında ortaya çıkmakta olup, şiddetli lezyonlar \% 20, hafif lezyonların ise \% 78 oranında görüldüğü tespit edilmiştir (10).

Araştırmalarda, kümeslerde refah düzeyini artırabilmek amacıyla hayvan odaklı ve yönetim kaynaklı önlemlerin alınabileceği belirtilmektedir. Buna göre öncelikli olarak hayvan odaklı, sonrasında ise yönetim kaynaklı önlemlerin alınması daha uygun olmaktadır $(28,12)$. Hayvan odaklı ölçümde, doğrudan hayvanların sağlık durumu ve davranışlarına göre değerlendirilme yapılmaktadır (76). Böylece refah koşullarının uygun biçimde tespit edilebilmesi sağlanmaktadır. Arnould ve ark. (5)'na göre kontakt dermatitler piliçlerin refahını değerlendirmek için uygulanabilir parametrelerdir. $\mathrm{Bu}$ derlemenin amacı kanatlılarda yaygın olarak görülen kontakt dermatiti tanımlamak, oluşum nedenlerini ve ölçme kriterlerini belirlemek, alınabilecek önlemleri tartışmaktır.

\section{Kontakt dermatit oluşumunda etkili faktörler}

Kontakt dermatit oluşumunda genotip, cinsiyet, canlı ağırlık, deri yapısı, rasyon, bağırsak enfeksiyonları, altlık özellikleri ve kümes koşulları gibi pek çok faktör etkili olabilmektedir $(49,50,59,61,73)$. Başlıca neden altlıktaki nem oranının (\% 30'dan yüksek nem) artmasıdır (4). Altlıktaki nem oranını etkileyen faktörler; altlı̆̆ın türü, altlık derinliği, aydınlatmadaki ışığın dağılımı, fotoperiyot, çevre sıcaklığı, havalandırma, nispi nem, suluk idaresi ve birim alandaki piliç yoğunluğudur $(49,63)$. Optimum kümes içi koşulların sağlanması kontakt dermatitin kontol altında tutulması için önemlidir. Sohsuebngarm ve ark. (63), yaptıkları çalışmaya göre kümes içi sıcaklık arttıkça ayak tabanı yanıklarının görülme oranı azalmış ama nispi nem düzeyi artması ve havalandırma hızının azalması durumda ise artmıştır. Kümes içinde birim alandaki hayvan yoğunluğunun kontakt dermatit oluşumuna etkisi bulunmaktadır. Matković ve ark., (48), düşük ve yüksek yerleşim yoğunluklarının (sırasıyla 12 piliç $/ \mathrm{m}^{2}$ ve 20 piliç $/ \mathrm{m}^{2}$ ) kontakt dermatite etkisini karşılaştırmışlar ve yüksek yoğunluktaki grupta ayak tabanı yanıklarının görülme sıklığının arttığını bildirmişlerdir. 
Bunun nedeni hareketlerdeki kısıtlanma olabilmektedir. Yapılan çalışmalarda piliçlerin birim alandaki yoğunluğunun azaltılmasıyla hareketliliğin arttığını ve böylece ayak tabanı yanıklarının görülme sıklığının azaldığını bildirmişlerdir $(40,65)$.

Kümeslerdeki kontakt dermatit oluşumundaki temel etken altık kalitesidir. Sıklıkla kullanılan altlık materyalleri talaş ve pirinç kavuzudur. Altlık materyali ne kadar emici özellikte ise kontakt dermatit görülme oranı da o kadar düşmektedir. Altlıktaki nem oranı gibi amonyak oranı ile düşük temas da kontakt dermatitin görülme sıklığını azaltmaktadır (37,58). Shepherd ve ark., (60) etçi piliç kümeslerinde altlıktaki nem seviyelerini kontrol etmek için altlık derinliğinin en az $7.6 \mathrm{~cm}$ olması gerektiğini belirtmişlerdir. Bazı işletmeler, kanatlı kümeslerinde kuru altlık koşullarını sağlayabilmek için yerden ısıtma yöntemi uygulamış ve hindilerde kontakt dermatitlerin görülme sıklığını azaltmada etkili olduğunu bildirmişlerdir (1). Özellikle hindilerin yetiştirilme süreleri etçi piliçlere göre daha uzun olduğu için, kümes içi altlığın kontrolü daha önemlidir (35). De Baere ve Zoons (19) yaptıkları çalışmada altlık materyali olarak odun talaşı ile buğday samanını karşılaştırılmıştır. Buna göre her iki altıkta da besi performansı etkilenmemekle birlikte odun talaşında ayak taban yanıkları daha düşük oranda görülmüştür. Bazı araştırmalarda, altlık kalitesini arttırmak amaciyla Yucca schidigera, sepiolit ve zeolit gibi doğal maddeler eklenmiştir $(55,56)$. Zeolitin de nem ve amonyak absorbe etme yeteneğinden dolayı altlık kalitesini arttırabileceği ve kontakt dermatit yönünden olumlu etkisi olabileceği öne sürülmüştür (20). Varol Avcılar ve ark. (69)'nın yaptıkları çalışmaya göre altlığa \% 25 ve \% 50 düzeylerinde sepiolit eklenmesi altlıktaki $\mathrm{pH}$, nem ve amonyak seviyelerinin azalmasına yardımcı olmuştur. Etçi piliç kümeslerindeki altlık üzerine yapılan araştırmalarda, peletlenmiş buğday samanının altlık kalitesini arttırdığı ve ayak tabanı yanıklarının görülme sıklığını azalttığı tespit edilmiştir $(39,77)$. Altlık materyali olarak peletlenmiş buğday samanı kullanılan etçi piliç kümeslerinde, besinin 24. ( $\mathrm{P}<0.001)$ ve 29. ( $\mathrm{P}<0.01)$ günlerinde saman talaşı ve parçalanmış kağıt kullanılanlara göre ayak tabanı yanıklarının daha düşük oranda görüldüğü, gögüs yanıklarının görülme sıklı̆̆ bakımından ise herhangi bir farklılığın olmadığı bildirilmiştir. Ayçiçeği çekirdeği kabuklarının kullanımı ise samana göre ayak tabanı ve gögüs yanıkları görülme oranlarını azaltmıştır (57).

Altlıktaki nem oranını artıran bir diğer faktör de beslemedir. Rasyonlara ham protein minimum seviyede katılmalı ve sindirilebilir optimum yoğunlukta amino asitler kullanılmalıdır (11). Rasyonlarda yüksek ham protein konsantrasyonları (soya küspesinin ana ve tek protein kaynă̆ı olarak kullanılması) ve yüksek elektrolit dengesi (Na ve K) dışkıyı daha sulu hale getirmekte, dolayısıyla altlıktaki nem ve amonyak oranını artırmaktadır (49). Soya küspesi, yüksek su tutma kapasitesine sahip lif, fermente olabilen karbonhidrat ve potasyum gibi daha yüksek su atılımından sorumlu olabilecek diğer bileşenleri içermektedir. Fazla protein böbreklerden katabolize olup ürik asit şeklinde atılırken yan ürün olarak da amonyak oluşmaktadır. Rasyonlarda K ve Na'nın aşırı kullanılması, yüksek su tüketimine neden olmakta bu da altlı̆̆ın daha çok ıslanmasına yol açmaktadır (70, 35). Öte yandan Abd El-Wahab ve ark. (2) yaptıkları araştırmada; 44 günlük piliçlerde ayak tabanı yanıklarının görülme sıklığı, rasyona alg katılan (\%4.5) yem ya da soya küspesine kısmen kolza küspesi katılan (\%14.5) yem ile beslenen piliçlerde, rasyona soya küspesi (\%32.5) katılan ya da kan unu katılan (\%4.5) yemlerle beslenenlere kıyasla belirgin olarak daha yüksek olduğu görülmüştür. Veldkamp ve ark. (70) hindiler üzerinde yaptıkları araştırmada; soya içeren rasyonun, soya içermeyen rasyonlara kıyasla altlıklarda daha yüksek nem içeriğine sahip olduğu ve bunun da ayak tabanı yanıklarının görülme oranını artırdığı tespit edilmiştir. Mısır veya buğday bazlı rasyonların, altlıktaki nem oranında etkili olmadığı, ancak mısır ile beslenen hindilerde görülen ayak tabanı yanıklarının buğday ile beslenenlerden daha yüksek olduğu görülmüştür (62). Öte yandan rasyondaki Zn ve biyotin eksiklikleri, epidermisin çevresel etkilere karşı direncini düşürebilmektedir (49). Aynı şekilde rasyondaki $\mathrm{Zn}, \mathrm{Cu}$ ve $\mathrm{Mn}$ gibi minerallerin deri yaralarının iyileşmesinde önemli olduğu tespit edilmiştir. Ayrıca probiyotik ve prebiyotiklerde bağırsak sağlığını iyileştirirerek altlık kalitesini olumlu etkilemektedir (14).

Kontakt dermatit oluşumunda kümes içi tasarım ve ekipmanların da etkili olabileceği dikkate alınmalıdır. Kümes ekipmanları arasında kullanılan suluk çeşidi ve suluk idaresi önemlidir. Ekstrand ve ark. (25) yaptıkları bir araştırmada nipel sulukların askılı suluklara göre altlığın daha az ıslanmasına neden olduğunu bildirmişlerdir. Aydınlatmanın etkisi de söz konusu olabilmektedir. Ayak tabanı yanıklarının oluşumu 5 lüks gibi düşük 1şık şiddetinde yetiştirilen piliçlerde 20 lüks gibi yüksek ışık şiddetinde yetiştirilenlere göre daha yüksek düzeyde çıkabilmektedir. Bunun nedeni olarak piliçlerin yüksek 1ş1k şiddetinde daha hareketli olduğu böylece kontakt dermatit oluşumunun azaldığı düşünülmüş̧ür (21). Aynı şekilde kesikli aydınlatma programının da ayak tabanı yanıklarını azalttığı 
kaydedilmiştir $(18,68)$. Chuppava ve ark $(15)$, kümeste farklı zemin tasarımlarının hindilerde ayak sağlığına etkisini incelemek amacıyla 4 farklı uygulama bölmesi oluşturmuşlardır. Birinci bölmede düz taban üzerine kuru odun talaşı, ikinci bölmede alttan 1sıtmalı düz taban üzerine kuru odun talaşı kaplanmıştır. Üçüncü bölmede alan ikiye bölünmüş olup yarısı kuru odun talaşı ile kaplanmış olup diğer yarısında plastik çıtalarla ızgara zemin oluşturulmuş, dördüncü bölmede ise tabanı tamamen 1zgara zeminle döşenmiş ve içine kum dökülmüştür. Buna göre 21. günde hindilerde ayak tabanı yönünden en iyi sonucu dördüncü grup vermiştir. Bu grupta ayaklar altlığa en az temas etmektedir ve ayaklarda geçici esneme hareketlerin yapılmasına olanak sağlamaktadır. Benzer bir çalışma piliçlerde kontakt dermatitin derin altık ve ızgaralı zeminde oluşum sıklığını belirlemek için yapılmıştır (13). Buna göre derin altlık, diz ve ayak tabanı yanıklarını artırmıştır. Fakat yaşla birlikte, göğüs ağırlığının da artmasıyla, göğüs yanıkları ızgaralı zeminde artmıştır $(\mathrm{P}<0.05)$. Bu sonuçlara göre 1zgaralı zeminde diz ve ayak tabanı yanıkları azalmıştır. Göğüs yanıklarından korunmak içinse bu sistemde yetiştirilecek piliçlerin kesim ağırlığının fazla yüksek olmaması dikkate alınmalıdır. Kümes tipi de kümes içi koşulları etkileyeceğinden altlık kalitesi ve zararlı gazların yoğunluğunu değiştirebilmektedir. Louton ve ark. (45)'nın yaptıkları çalışmada dışarı açılıp kapanabilen yarı-açık kümes (Louisiana tipi kümes) ile kapalı kümes tiplerini karşılaştırmışlardır. Söz konusu yarı-açık kümes tipinde, açıp-kapama için otomatik perde sistemi mevcuttur ve doğal havalandırma kullanılmaktadır. Bu yüzden kapalı kümeslere göre daha az maliyetli olmaktadır (45). Diğer yandan dış hava koşullarına bağlı olduğu için yüksek nem veya sıcak rüzgar gibi olumsuz durumlara da maruz kalabilmektedir. $\mathrm{Bu}$ tip kümeslerde, kapalı kümeslere oranla daha fazla amonyak ve karbondioksit gazı tespit edilmiş olup altlık kalitesi de olumsuz etkilenmiştir (45).

Genotip ile çevre etkileşimi ayak tabanı yanıklarının ortaya çıkmasında etkilidir (6). Genetik varyasyon ayak tabanı ve diz yanıklarına duyarlılıkta önemli bir faktördür (49). Kalıtım derecesi ayak tabanı için $0.31 \pm 0.12 \mathrm{ve} \mathrm{diz}$ yanıkları içinse $0.08 \pm 0.08$ olduğu bildirilmiştir (41). Yavaş ve hızlı büyüyen etçi piliçlerde ayak tabanı yanıklarının yaygınlık oranını karşılaştıran Kyvsgaard ve ark. (44); hızlı büyüyenlerde \% 48.7 yavaş büyüyenlerde ise \% 42.1 oranında ayak tabanı yanıklarının görüldügünü tespit etmişlerdir. Hindilerle ilgili yapılan bir araştırmada farklı dört hindi hibriti karşılaştırılmış, hızlı büyüyen hibritlerde daha erken ayak tabanı yanıklarının görüldüğü bildirilmiştir (36). Hızlı büyüyenlerde canlı ağırlık arttıkça yürüme yeteneğinde bozulmalar meydana gelmekte ve bunun sonucunda da ayak tabanı ve diz yanık oranları artmaktadır $(6,45)$. Yapılan çalışmalarda kemik gelişiminin, hızlı büyüyen etçi piliçleri olumsuz etkilediği bu nedenle yürüme kabiliyetinde bozulma olduğu (66), bacak zayıflığı ve sakatlığının ayak tabanı ve diz yanıklarına duyarlılığı artırdığı bildirilmiştir $(43,32)$. Erken büyüme dönemindeki hareketlilik, özellikle kemik ve kasları güçlendirerek dermatit oluşumunu engellemektedir (58). Vücut ağırlığı ile yürüme yeteneği arasında yüksek ve negatif korelasyon $(0.8)$ mevcuttur $(38,16)$. Ayrıca cinsiyet söz konusu olduğunda dişilere göre canlı ağırlığ daha fazla olan erkeklerde, kontakt dermatit görülme oranı dişilerden daha fazla olmaktadır (59). Hızlı büyüyen etçi piliç ve hindi hibritlerinde çoğu zaman göğüs bölgesinde tüylenmenin az olması göğüs yanıklarının gelişmesine neden olabilmektedir. Ayıca söz konusu hibritler ağır göğüs kasına sahip olduğu için yanıkların görülme oranı da artmaktadır (35).

\section{Kontakt dermatitlerde ölçüm kriterleri}

Kanatlılarda kontakt dermatitlerinin ölçülmesi, karkas değerlendirme işlemleri ile birlikte genellikle kesimhanelerde yapılmaktadır. Özellikle ayak tabanı yanıkları için bu ölçümler, tavuk ayaklarını besin olarak tüketen Uzak Doğu ülkeleri için oldukça önemlidir. Lezyonların derecesine göre sol ve sağ ayak tabanları ve dizler skorlama sistemi ile incelenmektedir (74). Ayak tabanı yanıkları genellikle 1- $1.5 \mathrm{~cm}$ çapında kahverengi- siyah kabuklu lezyonlardır. Lezyonların boyutu küçük çapta aşınmalar ya da derin dokuya kadar inen ülserleşme şeklinde olabilmektedir. Lezyonların derinliği, şiddetine göre; 1-2 mm ya da 5-6 mm arasında değişmektedir (22). Diz yanıkları başlıca dorsal tarsometatarsal eklem bölgesinde 2- $3 \mathrm{~cm}^{2}$ 'lik lezyonlardır. Burada aşınma ve bazen de kanama şekillenebilmektedir. Şiddetli lezyonlarda deri nekrotik ve kirli gri renkte görünmektedir. Göğüs yanıkları ise çeşitli şekil ve boyutlarda görülebilen göğüs derisindeki lezyonlardır. Şekilleri bazı durumlarda 2-3 ile 5-6 cm çapında yuvarlak ya da 3-4 ile 7-8 cm uzunluğunda şerit benzeri/ dikdörtgen biçiminde olabilmektedir. Şiddetli lezyonlarda deri altı dokularda ödem meydana gelebilmekte ya da yüzeysel göğüs kasları etkilenebilmektedir (22). 
Skorlama sisteminde çeşitli metotlar kullanılmaktadır. İkili puanlama sisteminde lezyonun olup olmamas1 şeklinde değerlendirilmektedir (34). Üçlü puanlama sisteminde ise lezyonlar derinlik veya şiddete göre derecelendirilmektedir (3). Bu puanlamaya göre lezyon yok veya çok hafif ise 0 , hafif lezyonlar için 1 ve şiddetli lezyonlar için 2 puan kullanılmaktadır (26). AB mevzuatı da üçlü puanlama sistemini kullanmaktadır (Resim 1). Puanlanan her bir ayak numunesi ile genel sürü ortalaması hesaplanmaktadır. Böylece hesaplanan ortalama sürü puanları, sonraki sürülerde birim alana yerleştirilecek olan hayvan sayısını belirmede kullanılmaktadır (35). Bu ölçümlerin haricinde 4, 5 veya 7 puanlık sistemler gibi daha ayrıntılı puanlama sistemleri de mevcuttur $(51,53)$. Fakat bazı araştırmalarda puanlama sisteminde basit puanlamanın yeterli olabileceği belirtilmektedir (33). Heitmann ve ark., (33), 4 puanlık sistemle 3 puanlık sistemi karşılaştırmış, görsel değerlendirmenin yanı sıra histopatolojik parametreler de kullanmışlardır. Buna göre lezyonlarda derinlik ve genişlik arasında bir kolerasyon (0.73) tespit edilmiş olup; az şiddetli $(1 ; 2)$ puanlamalar görsel ve histolojik değerlendirmelerle örtüştügü ancak çok şiddetli $(3 ; 4)$ puanlamalar arasındaki farklıı̆̆ıı çok önemli olmadığını vurgulamışlardır.

Son yıllarda, sürü yönetiminin daha kolay sağlanabilmesi için yeni teknolojiler geliştirilmektedir $(72,9,7)$. Otomatik bilişim sistemleri, etçi piliçlerin davranışları, konumları, hareketleri, büyümesi ve refahını izlemek için kullanılmaya başlanmıştır. Bu gözetleme sistemlerinin avantajı, hayvanlara dokunmadan, rahatsız etmeden ve stres oluşturmadan sürekli biçimde bilgi toplanabilmesidir (67). Ticari etçi piliç ve hindi sürülerinin çiftlik içi refah değerlendirmesi için kullanılan transekt yöntemi mobil uygulamalar ile geliştirilmiştir (i-WatchBroiler ve iWatchTurkey) (47, 46). Transekt yönteminde, hayvanların suluk ve yemlik hatları arasında gerçekleştirdikleri yürüyüşler esas alınmakta ve önceden belirtilmiş etçi piliç refahı parametrelerine (24) göre değerlendirilmektedir. Ben Sassi ve ark., (8) yaptıkları çalışmada transekt methodunun i-WatchBroiler uygulaması ile birlikte kullanımının ticari etçi piliç kümeslerinin değerlendirmesinde daha hızlı, etkili, pratik ve uygulanabilir olduğunu belirtmişlerdir. Bu yöntem, refahla ilgili sorunları ve ekonomik kayıpları azaltmak için değerli bir araç olarak düşünülebilmektedir. Ayrıca daha gelişmiş teknolojilerde insan gözlem faktörünü minimuma indirecek makineler de geliştirilmektedir. Bu makineler insan değerlendirmesi ile kıyaslanırsa; kullanım kolaylığı, nesnellik ve kapsamlık gibi potansiyel avantajlara sahiptir. Son araştırmalar, ticari sürülerdeki etçi piliç aktivitesinin ayak tabanı yanıklarının yaygınlığını tahmin etmek ve görülme oranını en aza indirmek için oldukça elverişli olduğunu saptamışlardır (17).

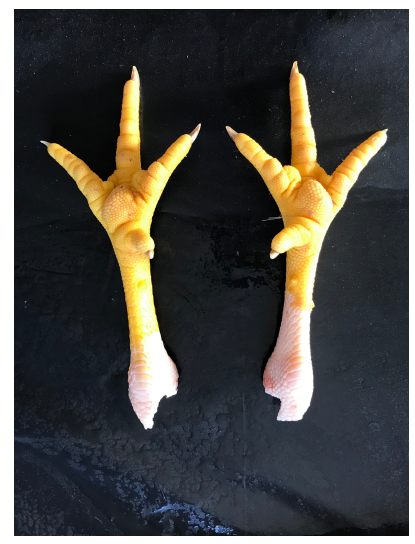

a

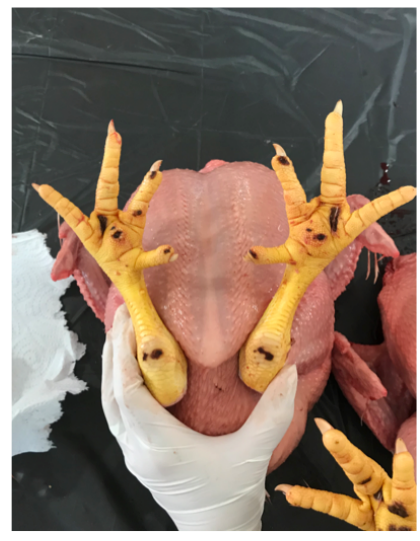

b

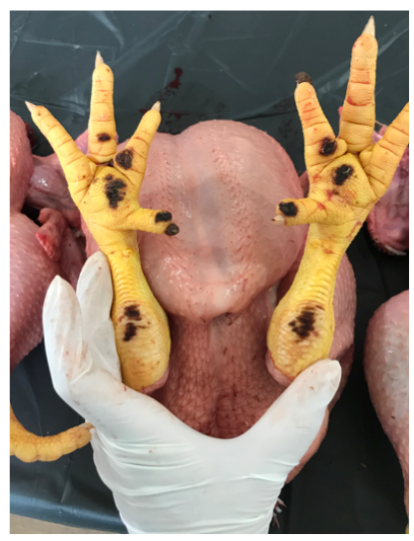

C

Şekil 1: Üçlü puanlama sistemi (a) lezyon yok, 0 (b) az-orta şiddetli lezyon, 1 (c) şiddetli lezyon, 2

Figure 1: Triple scoring system (a) no lesion, 0 (b) mild to moderate lesion, 1 (c) severe lesion, 2 


\section{Sonuç}

Kontakt dermatit, özellikle etçi kanatlı yetiştiriciliğinde daha sık görülen önemli bir refah sorunudur. Bu hastalığın oluşumunda temas edilen altlığın türü, kalitesi ve derinliği ile kümes içindeki nem, sıcaklık, aydınlatma ve havalandırma düzeyleri, yerleşim sıklığı, bağırsak sağlı̆̆ı, kümes tipi ve ekipmanları önemli rol oynamaktadır. Altlıklı sistemlerde yetiştirilen kanatlı hayvanlarda, altlıktaki nem oranının yüksek olması durumunda ayak tabanı ve diz yanıklarının görülme riski artmaktadır. Göğüs yanıkları, ayak tabanı ve diz yanıkları ile benzer bir etiyolojiye sahiptir. Bununla birlikte göğüs yanıkları zayıf göğüs tüylenmesi ve yüksek canlı ağrlık ile de ilişkili olabilmektedir. Kontakt dermatit oluşumunda bir diğer önemli faktör ise genotiptir. Hızlı büyüyen hibritlerde bu durum daha fazla görülmektedir. Bunun nedeni hızlı canlı ağırlık artışına bağlı olarak görülen yetersiz kemik gelişimi ve yürüyüş bozuklukları sonucunda daha fazla oturma davranışının görülmesidir. Kümeslerde kaliteli altlıkların kullanılması, yerleşim sıklığının yoğun olmaması ve rasyonun iyi ayarlanması oldukça önemlidir. Araştırmalar, kontakt dermatitin görülme oranını düşürmek için çevre koşullarının optimum seviyede tutulması gerektiğini vurgulamışlardır.

\section{Çıkar Çatışması Beyanı}

Makalenin yazarları arasında bu derleme çalışması kapsamında herhangi bir kişisel ve finansal çıkar çatışması bulunmamaktadır.

\section{Yazar Katkısı Beyanı}

Fikir/kavram: Hilal Çapar Akyüz

Kaynak taraması: Hilal Çapar Akyüz

Makalenin yazımı: Hilal Çapar Akyüz, E. Ebru Onbaşılar

\section{Etik Onay}

$\mathrm{Bu}$ makaledeki sunulan verilerin, bilgilerin ve dokümanların akademik ve etik kurallar çerçevesinde elde edildiği, tüm bilgi, belge, değerlendirme ve sonuçlarının bilimsel etik ve ahlak kurallarına uygun olarak sunulduğuna dair yazarlardan etik beyan alınmıştır

\section{Kaynaklar}

1. Abd El-Wahab A, Beineke A, Beyerbach M, Visscher CF, Kamphues J (2011): Effects of floor heating and litter quality on the development and severity of foot pad dermatitis in young turkeys. Avian Diseases, $\mathbf{5 5}$, 429-434.

2. Abd El-Wahab A, Visscher C, Kamphues J (2018): Impact of different dietary protein sources on performance, litter quality and foot pad dermatitis in broilers. Journal of Animal and Feed Sciences, 27, 148154.

3. Allain V, Mirabito L, Arnould C, Colas M, Le Bouquin S, Lupo C, Michel V. (2009): Skin lesions in broiler chickens measured at the slaughterhouse: relationships between lesions and between their prevalence and rearing factors. British Poultry Science, 50, 407-417.

4. Amer MM (2020): Footpad dermatitis (FPD) in chickens. The Korean Journal of Food \& Health Convergence, 6, 11-16.

5. Arnould, C., A. Butterworth, and U. Knierim. (2009): Standardisation of clinical scoring in poultry. 7-30. B. Forkmann, L. Keeling (ed.) In Assessment of Animal Welfare Measures for Layers and Broilers. Cardiff University Press, Cardiff, UK.

6. Ask B (2010): Genetic variation of contact dermatitis in broilers. Poultry Science, 89, 866-875.

7. Ben Sassi N, Avero's X, Estevez I (2016): Technology and poultry welfare. Animals, 6, 62-83. 
8. Ben Sassi N, Aver'os X, Estevez I (2019): The potential of the transect method for early detection of welfare problems in broiler chickens. Poultry Science, 98, 522-532.

9. Berckmans D. (2014). Precision livestock farming technologies for welfare management in intensive livestock systems. Revue Scientifique et Technique, 33, 189-196.

10. Berg CC (1998): Foot-pad dermatitis in broilers and turkeys. Doctoral thesis, Swedish University of Agricultural Sciences, Uppsala.

11. Bilgili SF, Hess JB, Donald J, Fancher B (2010): Practical considerations for reducing the risk of pododermatitis. Aviagen Brief, 1, 1-8.

12. Butterworth A (2013): On-farm broiler welfare assessment and associated training. Brazilian Journal of Poultry Science, 15, 71-77.

13. Çavuşoğlu E, Petek M, Abdourhamane IM, Akkoc A, Topal E (2018): Effects of different floor housing systems on the welfare of fast-growing broilers with an extended fattening period. Archives Animal Breeding, 61, 9-16.

14. Chen J, Tellez G, Escobar J, Vazquez-Anon M (2017): Impact of Trace Minerals on Wound Healing of Footpad Dermatitis in Broilers. Scientific Reports, 7, 1-9.

15. Chuppava B, Visscher C, Kamphues J (2018): Effect of different flooring designs on the performance and foot pad health in broilers and turkeys. Animals, 8, 70.

16. Dawkins MS, Donnelly CA, Jones TA (2004): Chicken welfare is influenced more by housing conditions than by stocking density. Nature, 427, 342-344.

17. Dawkins MS, Roberts SJ, Cain RJ, Nickson T, Donnelly CA (2017): Early warning of footpad dermatitis and hockburn in broiler chicken flocks using optical flow, bodyweight and water consumption. Veterinary Record, 180, 499-499.

18. de Baere K. (2008): Lichtschema's bij vleeskuikens. Pluimvee 46 [in Dutch].

19. de Baere, K. and Zoons, J. (2004) Strooiselmateriaal in pluimveestallen. Pluimvee 40 [in Dutch].

20. de Oliveira MC, Gonçalves BN, Pádua GT, da Silva VG, da Silva DV, Freitas AI (2015): Treatment of poultry litter does not improve performance or carcass lesions in broilers. Revista Colombiana de Ciencias Pecuarias, 28, 331-338.

21. DEFRA (2010): Foot pad dermatitis and hock burn in broilers: risk factors, aetiology and welfare consequences. Department of Agriculture, Food and Rural Affairs, London, United Kingdom.

22. Dinev I, Denev S, Vashin I, Kanakov D, Rusenova N (2019): Pathomorphological investigations on the prevalence of contact dermatitis lesions in broiler chickens. Journal of Applied Animal Research, 47, 129134.

23. EFSA (2010): EFSA Panel on Animal Health and Welfare. Scientific opinion on the influence of genetic parameters on the welfare and the resistance to stress of commercial broilers. EFSA Journal, 8, 1666.

24. EFSA Panel on Animal Health and Welfare (2012): Scientific opinion on the use of animal-based measures to assess welfare of broilers. EFSA Journal, 10, 2774.

25. Ekstrand C, Algers B, Svedberg J (1997): Rearing conditions and foot-pad dermatitis in Swedish broiler chickens. Preventive Veterinary Medicine, 31, 167-174.

26. Ekstrand C, CArpenter TE, Andersson I, Algers B (1998): Prevalence and control of foot-pad dermatitis in broilers in Sweden. British Poultry Science, 39, 318-324.

27. European Union (EU) (2007): Council directive 2007/43/EC laying down minimumrules for the protection of chickens kept for meat production. Official Journal of the European Union, 182, 19-28.

28. Forkman B (2009). Assessment of animal welfare measures for layers and broilers. Univ., School of City and Regional Planning.

29. Frosch PJ, John SM (2011): Clinical aspects of irritant contact dermatitis. In Contact Dermatitis. 305-345. Springer, Berlin, Heidelberg.

30. Greene JA, McCracken RM, Evans RT (1985): A contact dermatitis of broilers-Clinical and pathological findings. Avian Pathology, 14, 23- 38. 
31. Hartcher KM, Lum HK (2020). Genetic selection of broilers and welfare consequences: a review. World's Poultry Science Journal, 76, 154-167.

32. Haslam SM, knowles TG, Brown SN, Wilkins LJ, Kestin SC, Warriss PD, Nicol CJ (2007): Factors affecting the prevalence of foot pad dermatitis, hock burn and breast burn in broiler chicken. British Poultry Science, 48, 264-275.

33. Heitmann S, Stracke J, Petersen H, Birgit Spindler B, Kemper N (2018): First approach validating a scoring system for foot-pad dermatitis in broiler chickens developed for application in practice. Preventive Veterinary Medicine, 154, 63-70.

34. Hocking PM, Mayne RK, Else RW, French NA, Gatcliffe J (2008): Standard European footpad dermatitis scoring system for use in turkey processing plants. World's Poultry Science Journal, 64, 323-328.

35. Hocking PM, Veldkamp T (2019): Poultry Feathers and Skin: The Poultry Integument in Health and Welfare. 70-83. In OA Olukosi, V Olori, A Helmbrecht, S Lambton, N French (Ed), Contact Dermatitis in Domestic Poultry (No. 32). CABI, UK.

36. Hocking PM, Wu K (2013): Traditional and commercial turkey show similar susceptibility to foot pad dermatitis and behavioural evidence of pain. British Poultry Science, 54, 281-288.

37. Kaukonen E, Norring M, Valros A (2016): Effect of litter quality on foot pad dermatitis, hock burns and breast blisters in broiler breeders during the production period. Avian Pathology, 45, 667-673.

38. Kestin SC, Gordon S, Su G, Sorensen P (2001): Relationship in broiler chickens between lameness, liveweight, growth rate and age. Veterinary Record, 148, 195-197.

39. Kheravii SK, Swick RA, Choct M, Wu SB (2017): Potential of pelleted wheat straw as an alternative bedding material for broilers. Poultry Science, 96, 1641-1647.

40. Kiani A, von Borstel UK (2019): Impact of different group sizes on plumage cleanliness and leg disorders in broilers. Livestock Science, 221, 52-56.

41. Kjaer JB, Su G, Nielsen BL, Sorensen P (2006): Foot pad dermatitis and hock burn in broiler chickens and degree of inheritance. Poultry Science, 85, 1342-1348.

42. Krautwald-Junghanns ME, Bergmann S, Erhard MH, Fehlhaber K, Hübel J, Ludewig M, MittererIstyagin H Ziegler N, Bartels T (2013): Impact of selected factors on the occurrence of contact dermatitis in turkeys on commercial farms in Germany. Animals, 3, 608-628.

43. Kristensen HH, Perry GC, Prescott NB, Ladewig J, Ersbøll AK, Wathes CM (2006): Leg health and performance of broiler chickens reared in different light environments. British Poultry Science, 47, 257-263.

44. Kyvsgaard NC, Jensen HB, Ambrosen T, Toft N (2013): Temporal changes and risk factors for foot-pad dermatitis in Danish broilers. Poultry Science, 92, 26-32.

45. Louton H, Bergmann S, Reese S, Erhard M, Bachmeier J, Rösler B, Rauch E (2018): Animal- and management-based welfare indicators for a conventional broiler strain in 2 barn types (Louisiana barn and closed barn). Poultry Science, 97, 2754-2767

46. Marchewka J, Estevez I, Vezzoli G, Ferrante V, Makagon MM (2015): The transect method: a novel approach to on-farm welfare assessment of commercial turkeys. Poultry Science, 94, 7-16.

47. Marchewka J, Watanabe TTN, Ferrante V, Estevez I (2013): Welfare assessment in broiler farms: transect walks versus individual scoring. Poultry Science, 92, 2588-2599.

48. Matković K, Marušić D, Ostović M, Pavičić Z, Matković S, Kabalin AE, Lucić H (2019): Effect of litter type and perches on footpad dermatitis and hock burn in broilers housed at different stocking densities. South African Journal of Animal Science, 49, 546-554.

49. Mayne RK (2005): A review of the aetiology and possible causative factors of foot pad dermatitis in growing turkeys and broilers. World's Poultry Science Journal, 61, 256-267.

50. Mayne RK, Else RW, Hocking PM (2007a): High litter moisture alone is sufficient to cause footpad dermatitis in growing turkeys. British Poultry Science, 48, 538-545. 
51. Mayne RK, Powell F, Else RW, Kaiser P, Hocking PM (2007b): Foot pad dermatitis in growing turkeys is associated with cytokine and cellular changes indicative of an inflammatory immune response. Avian Pathology, 36, 453-459.

52. McFerran JB, McNulty MS, McCracken RM, Greene JA (1983): Enteritis and associated problems. 129138. Proc. International Union of Immunological Societies: Disease Prevention and Control in Poultry Production. No. 66, University of Sydney, Australia.

53. McKeegan D. (2010): Foot pad dermatitis and hock burn in broilers: risk factors, aetiology and welfare consequences. Research Project Final Report, Faculty of Veterinary Medicine, University of Glasgow, Scotland, UK.

54. Meluzzi A, Fabbri C, Folegatti E, Sirri F (2008): Survey of chicken rearing conditions in Italy: effects of litter quality and stocking density on productivity, foot dermatitis and carcase injuries. British Poultry Science, 49, 257-264.

55. Onbaşılar EE, Erdem E, Ünal N, Kocakaya A, Torlak E (2013): Effect of Yucca schidigera spraying in different litter materials on some litter traits and breast burn of broilers at the fifth week of production. Kafkas Üniversitesi Veteriner Fakültesi Dergisi, 19, 749-753.

56. Onbaşılar EE, Erdem E, Ünal N, Kocakaya A, Torlak E (2014): Effect of Yucca schidigera additions to different litter materials on broiler performance, footpad dermatitis and litter characteristics. European Poultry Science, 78.

57. Popescu S, EI Mahdy C, Diugan EA, Petrean AB, Borda C (2018): The effect of bedding type on the welfare quality of broiler chickens. Scientific Papers: Animal Science and Biotechnologies, 51, 86-92.

58. Riber AB, Van De Weerd HA, De Jong IC, Steenfeldt S (2017): Review of environmental enrichment for broiler chickens. Poultry Science, 97, 378-396.

59. Shepherd EM, Fairchild BD (2010): Footpad dermatitis in poultry. Poultry Science, 89, 2043-2053.

60. Shepherd EM, Fairchild BD, Ritz CW (2017): Alternative bedding materials and litter depth impact litter moisture and footpad dermatitis. Journal of Applied Poultry Research, 26, 518-528.

61. Sherlock L, McKeegan DEF, Cheng Z, Wathes CM, Wathes DC (2012): Effects of contact dermatitis on hepatic gene expression in broilers. British Poultry Science, 53, 439-452.

62. Smith A, Rose SP, Wells RG, Pirgozliev V (2000): Effect of excess dietary sodium, potassium, calcium and phosphorus on excreta moisture of laying hens. British Poultry Science, 41, 598-607.

63. Sohsuebngarm D, Kongpechr S, Sukon P (2019): Microclimate, Body Weight Uniformity, Body Temperature, and Footpad Dermatitis in Broiler Chickens Reared in Commercial Poultry Houses in Hot and Humid Tropical Climates. World, 9, 241-248.

64. Souillard R, Répérant J-M, Experton C, Huneau-Salaun A, Coton J, Balaine L, Le Bouquin S (2019): Husbandry practices, health, and welfare status of organic broilers in France. Animals, 9, 1-12.

65. Tahamtani FM, Pedersen IJ, Riber AB (2020): Animal well-being and behavior - Effects of environmental complexity on welfare indicators of fast-growing broiler chickens. Poultry Science, 99, 21-29.

66. Tullo E, Aletti G, Micheletti A, Naldi G, Fernandez AP, Vranken E, ... , Guarino, M (2018): The influence of microclimate on the development of foot pad dermatitis in broilers. In 10th International Livestock Environment Symposium (ILES X), American Society of Agricultural and Biological Engineers.

67. Tullo E, Fontana I, Peña Fernandez A, Vranken E, Norton T, Berckmans D, Guarino M (2017): Association between environmental predisposing risk factors and leg disorders in broiler chickens. Journal of Animal Science, 95, 1512-1520.

68. Van Harn J (2009): Invulling lichteisen EU-welzijnsrichtlijn voor vleeskuikens - vier lichtschema's vergeleken. ASG-Rapport 172 [in Dutch].

69. Varol Avcılar Ö, Kocakaya A, Onbaşılar EE, Pirpanahi M (2018): Influence of sepiolite additions to different litter materials on performance and some welfare parameters of broilers and litter characteristics. Poultry Science, 97, 3085-3091.

70. Veldkamp T, Hocking PM, Vinco LJ (2017): Less foot pad lesions by nutritional adjustments. In Proceedings of the 11th Turkey Science and Production Conference, 24-25. 
71. Wang G, Ekstrand C, Svedberg J (1998): Wet litter and perches as risk factors for the development of foot pad dermatitis in floor-housed hens. British Poultry Science, 39, 191-197.

72. Wathes CM, Kristensen HH, Aerts JM, Berkmans D (2008): Is precision livestock farming an engineer's daydream or nightmare, an animal's friend or foe, and a farmer's panacea or pitfall?. Computers and Electronics in Agriculture, 64, 2-10.

73. Weber C, Sinclair A, Veldkamp T, Vinco LJ, Hocking PM (2015): Footpad dermatitis and pain assessment in turkey poults using analgesia and objective gait analysis. British Poultry Science, 56, 522-530.

74. Welfare Quality (2009): Welfare Quality ${ }^{\circledR}$ assessment for poultry: broilers, laying hens. A. Butterworth, C. Arnould, T. Fiks van Niekerk, I. Veissier, L. Keeling, G. van Overbeke, V. Bedaux, (Ed). Welfare Quality® Consortium, Lelystad, the Netherlands.

75. Wyneken CW, Sinclair A, Veldkamp T, Vinco LJ, Hocking PM (2015): Footpad dermatitis and pain assessment in turkey poults using analgesia and objective gait analysis. British Poultry Science, 565, 522530.

76. Zapf R, Schultheiß U, Archilles W, Schrader L, Knierim U, Herrmann H-J, Brinkmann J, Winckler C (2015): Tierschutzindikatoren: Vorschläge für die betriebliche Eigenkontrolle. Kuratorium für Technik und Bauwesen in der Landwirtschaft (KTBL), Darmstadt, Germany.

77. Zikic DI, Djukic-Stojcic MI, Bjedov SI, Peric LI, Stojanovic SI, Uscebrka GI (2017): Effect of litter on development and severity of foot-pad dermatitis and behavior of broiler chickens. Brazilian Journal of Poultry Science, 19, 247-254. 